\title{
Una mirada filosófica sobre la literatura
}

\author{
JOSÉ M. GONZÁLEZ GARCÍA
}

Toda la extensa obra de Aranguren está atravcsada por la literatura. De hecho no es mera casualidad que el análisis de la poesía de San Juan de la Cruz fuera el objeto del primer libro que escribiera en 1943 con intención de publicar, si bien no viera la luz de la imprenta hasta varios años más tarde. Como es bien sabido, el primer libro publicado por Aranguren fue La filosofía de Eugenio D'Ors ${ }^{1}$. La reflexión sobre D'Ors fue creciendo en años posteriores hasta desembocar en una edición muy ampliada del libro al que se añadieron bastantes textos más. Uno de ellos, el titulado «Sentido ético de las ficciones novelescas orsianas", había sido escrito en 1955 y publicado inicialmente en Crítica y meditación ${ }^{2}$. Aranguren descubre en las narraciones de D'Ors un paralelismo con los planteamientos filosóficos de este autor, una continuidad entre filosofía y literatura. Así, por ejemplo, escribe:

El polo negativo de la filosofía y de la ciencia de la cultura de Eugenio D'Ors están plásticamente figurados en Gualba, la de mil voces: la abrupta escisión de la razón y la naturaleza, el insalvable dualismo de lo clásico y lo barroco — con su subespccie, lo romántico- se hallan presentes aquí, vistos, no en su anverso de luz, sino en su sombrío reverso. (...) Pero también a través de este relato se advierte la caracterización última de la filosofia general y de la ciencia de la cultura de Eugenio D'Ors; quiero decir, su determinación ética ${ }^{3}$.

Por otro lado, la preocupación de Aranguren por un catolicismo abierto a la cultura moderna le lleva en sus obras fundamentales de los años cincuenta a ocuparse con la literatura. Así, en Crítica y meditación aparecen sus reflexiones sobre la relación entre poesía y existencia humana o acerca de la necesidad de la filosofia para la crítica literaria. En Catolicismo y protestantismo como formas de existencia (1952) dedica la parte tercera a la influencia de la poesía de Stefan George sobre la cultura católica alemana y a la reflexión acerca del talante religioso de Miguel de Unamuno. Catolicismo día tras día (1955) contenía sus estudios sobre poesía española, especialmente el titulado «Esperanza y desesperanza de Dios en la vida de Antonio Machado», y sus análisis de las obras de André Gide y Franz Kafka. Leídos desde la sensibilidad actual, nos resultan extrañas tanto la reacción de la jerarquía eclesiástica contra Aran-

Madrid, Ediciones y Publicaciones Españolas, 1945.

${ }^{2}$ Madrid, Taurus, 1957.

${ }^{3}$ J. L. L. Aranguren, La filosofia de Eugenio D'Or, en sus Obras Completas editadas por Feliciano Blázquez, Madrid, Trotta, 1994, vol. 1, p. 77. 
guren como también cl intento constante de este último de aplicar categorías religiosas a la interpretación de los textos literarios. Pero es necesario leer a Aranguren como testimonio vivo de una época en la que cualquier novedad interpretativa de la cultura del momento podía hacer recordar la frase de D. Quijote: «iCon la iglesia hemos topado, amigo Sancho!»

En los años setenta ve la luz el librito El cristianismo de Dostoievski (1970), concebido inicialmente como prólogo a una edición de las Obras Completas del novelista, y la colección de ensayos titulada Estudios literarios (1976). En este libro - ampliado más tarde, a comienzos de los años noventa, en una edición del Círculo de Lectores- se recogen los principales artículos sistemáticos de Aranguren sobre literatura en lengua castellana, a los que se añade un pequeño estudio sobre la poesía catalana de Carles Riba ${ }^{4}$. Algunos de estos artículos proceden de introducciones a la obra de diferentes autores y otros son el fruto de la docencia, bien en la Universidad de Madrid donde al hilo de su enseñanza de ética y sociología impartió seminarios sobre «Moralistas españoles» o sobre «Moralistas franceses», bien en la Universidad de California, en la que intentó aproximar a los estudiantes norteamericanos a San Juan de la Cruz o a la novela española contemporánea.

Por otro lado, a lo largo de varias décadas ha ejercido Aranguren la crítica literaria en diversos periódicos, especialmente en La Vanguardia de Barcelona, así como en Informaciones y El País de Madrid. Muchos de estos artículos han sido recogidos en libros como El oficio de intelectual y la crítica de la crítica (1979) y otros aguardan una nueva publicación en el último volumen de sus Obras Completas, dedicado precisamente a los estudios literarios y autobiográficos. No deja de ser acertada esta confluencia de los dos tipos de escritos en un mismo volumen, pues Aranguren ha insistido en muchas ocasiones acerca de la proximidad entre literatura y vida, entre los textos literarios y los textos en que consiste nuestra vida, ya que cada uno de nosotros es un stexto vivo" que se va narrando y que debe ser, tambiên, objeto de interpretación.

Dada la multiplicidad de textos en los que Aranguren se refiere, de una u otra manera, a la literatura y ante la imposibilidad de hacer justicia a todos ellos, voy a intentar en las páginas que siguen ceñirme a las que me parecen algunas de sus tesis centrales.

\section{Los usos morales de la literatura}

Cuando en 1958 publica Aranguren su Etica -concebida como manual para los estudiantes y como libro de investigación que se inserta en la tradición de autores como Aristóteles, Santo Tomás y Zubiri, si bien dotando a esta tradición de elementos originales - señala en el último capítulo una serie de

- La única excepción sería el artículo sobre las Confesiones de San Agustín incorporado a la edición del Circulo de Lectores, Madrid, 1991, pp. 7-20. 
reflexiones sobre la enseñanza de la ética. Sólo me voy a referir aquí a la relacionada con el tema de estas páginas. Para intentar poner remedio al aburrimiento en que suele caer la enseñanza de la ética, propone Aranguren lo siguiente:

Me parece que la solución está en la atención a la realidad, es decir, a la experiencia, a la vida, a la historia, a la religión y, en fin, a la literatura como expresión de todo esto. Lo cual de ninguna manera es una «concesión", pues, como hemos visto a to largo de este libro, de todo ello y no de abstracciones ha de alimentarse la ética. Creo, por tanto, que al buen profesor de ética le es imprescindible un hondo conocimiento de la historia de la moral y de las actitudes morales vivas. Ahora bien, éstas donde se revelan es en la literatura. El recurso a la mejor literatura, a más de poner al discípulo en contacto con las formas reales y vigentes de la vida moral, presta a la enseñanza una fuerza plástica incomparable $y$, consiguientemente, una captación del interés del alumno ${ }^{5}$.

Pero este papel «ancillar» de la literatura respecto a la enseñanza de la ética no es nada fácil. No se deben rebajar los contenidos y sacrificarlos a la amenidad. Y por otro lado, según concluye el propio Aranguren, esta utilización de la literatura por parte del profesor de ética es complicada, pues requiere dos cualidades que dichos profesores no suelen tener: un gran conocimiento de la literatura - cspecialmente de la contemporánea, que es la que más puede motivar a los estudiantes - y ser un buen crítico literario. Ni que decir tiene que Aranguren reunía estas dos cualidades de manera ejemplar, como lo demuestran algunos de sus cursos sobre literatura contemporánea en la Universidad de California, en Santa Bárbara, y el hecho de haberse ocupado durante toda su vida de la crítica literaria.

\section{La filosofia española hay que buscarla en la literatura}

En diversas ocasiones a lo largo de su extensa obra se hace eco Aranguren de la tesis según la cual la filosofía española hay que buscarla más en nuestra tradición literaria que en los tratados propiamente filosóficos. A mi juicio, su formulación más explicita scría la siguiente:

Muchas veces se ha escrito, desde Unamuno y Ganivet, y lo mismo por españoles que por extranjeros, que el «lugar» en que se ha de buscar y se encuentra la filosofia española no es el tratado de filosofía, sino la literatura. $\Lambda$ sí, la filosofía poético-mística de San Juan de la Cruz, la profunda filosofia encerrada en el Quijote, la filosofia moral de Quevedo y Gracián, la filosofía picaresca, la meditación dramática sobre el mundo y la vida de Calderón de la Barca. Y probablemente otro tanto cabe decir de la teología,

'J. L. L. Aranguren, Etica, Madrid, Revista de Occidente, 1958, p. 421. El propio Aranguren afirma que una versión anterior de este último capítulo había sido publicada en el núm. 26 de la Revista de Educación, bajo el título de «La enseñanza de la ética». 
pese a la obra formalmente teológica de autores como Molina, Bánez y, tanto por lo que se refiere a la teologia como a la filosofia, Suárez ${ }^{6}$.

Expresada esta tesis como primera frase de su estudio sobre teología y teatro en Tirso de Molina no hay que entenderla como una reivindicación casticista del ique inventen o filosofen ellos!, sino como una expresión de la importancia de la literatura para el pensamiento filosófico y teológico español. Pero esta unión entre pensamiento y literatura funciona de manera diferente en las diversas circunstancias históricas en lo que podemos entender como una tesis de sociología de la literatura. De hecho, Aranguren distingue con cuidado entre la situación de nuestros siglos xVI y xVIr. Mientras que en el siglo XVI, en las obras de Juan de la Cruz o Teresa de Ávila se trata de una teología fundamental intuida poéticamente, de una búsqueda de «nuevas vías de unión con la divinidad y de saber-sabor de Dios», en el caso de la gran literatura del siglo xvIr, ya abiertamente contrarreformista, se trata de «una literaturización de la teología pastoral predicada desde los púlpitos», en una obra de propaganda religiosa que es, al mismo tiempo, propaganda política. Mientras que en un caso se trata de la búsqueda de nuevas formas de expresión a través de la poesía de lo que es inexpresable, en el otro nos encontramos con la utilización de la literatura $y$, sobre todo, del teatro como un medio de propaganda que transmite contenidos religiosos y políticos en una incipiente sociedad de masas a través de los «medios de comunicación de masas» más avanzados de la época.

\section{Poesía y existencia. Conjunción de lo ético, lo poético y lo religioso}

Hace ya algunos años, Pedro Cerezo señalaba la clave literaria a la que ha sido siempre proclive Aranguren y afirmaba la conjunción existencial entre lo ético y lo poético en toda su obra. Ciertamente, ya en uno de sus primeros libros de crítica literaria se da una reivindicación de Rilke y de la poesía como expresión de «la experiencia de la vida», pues sólo a través de la maduración de la propia experiencia es posible la labor poética:

Para Rilke la poesía - como para Heidegger la metafísica - es el acontecimiento radical de la existencia. La vida es en sí misma poética; toda experiencia entraña poesia y no hay otra que la entrañada en el vivir; sólo perduran los «versos en los que ha entrado el destino»?

- J. L. L. Aranguren, «Teología y teatro en Tirso de Molina*, en El oficio de intelectual y la crítica de la critica (Obras Completas, Madrid, Trotta, 1996, vol. 5, pp. 344-345). El mismo artículo también aparece recogido en la nueva versión de los Estudios literarios de Aranguren publicada por el Circulo de Lectores, Madrid, 1991.

' J. L. L. Aranguren, Crítica y meditación, ed. cit , p. 24. 
En esta defensa de una poesía que vuelve los ojos a la vida de cada día, a la humilde trama de toda existencia humana cree descubrir una relación entre Rilke y la poesía española de la generación poética de 1936 o también de Antonio Machado. $Y$ es que se trata de una poesía que quiere ser $-y$ Aranguren pide a los poetas perdón por la palabra- existencial. Porque cllos están haciendo, al igual que la filosofía de la época, una reflexión sobre la existencia, sobre el tiempo de la vida, sobre nuestra vida que es tiempo:

La existencia concreta, vivida, poética, de cada uno de nosotros, sólo hay una manera de definirla: contándose el poeta a sí mismo, contando el tiempo concreto, lleno, vivido, que desde la primera oscura noticia, del primer acontecimiento infantil, hasta el penúltimo toque a la pausada elaboración de una «buena muerte», constituye al hombre ${ }^{8}$.

En esta evolución hacia la poetización de la existencia, hacia una «poesía del tiempo concreto y real», hay un camino de encuentro con la filosofía y también - insiste el Aranguren de aquellos años-con la religión. Así comienza su artículo sobre «Nuestro tiempo y la poesía»:

En otro lugar hemos dado cuenta del ensayo de Heidegger sobre Rilke en su nuevo libro Holzwege. La filosofía más importante de nuestro tiempo se vuelve más y más hacia la poesía - hacia la poesía que es salir de nuestra casa, «sosegada» o sin sosiego, ponerse a la puerta del alma o en el umbral del mundo, y esperar alli, con los ojos abiertos o muy cerrados para no dormir, el regreso del Viajero inopinado, que es siempre Dios-. La filosofía, fatigada de ese su largo paseo solitario que ha sido la época moderna, busca la compañía de la poesía, que es, de una manera u otra, religión ${ }^{9}$.

Y sin embargo, cuando al final de este mismo artículo se pregunta Aranguren temerariamente por cómo será la poesía del futuro, responde, por un lado, que se tratará de poesía religiosa de una u otra manera, aunque sea a través de la irreligiosidad. $Y$ por otro, señala la necesidad de trascender, de ir más allá de nuestra vida, porque el ciclo poesía-existencia ya ha tocado a su fin: hay que ir más allá de la poesía de la existencia hacia la poesía del ser. Y esto parece consistir en que el poeta ha de abrir nuevos caminos, ha de ser mensajero de lo nuevo. Con toda la importancia de la poetización de la vida real hay que dar un paso más: «el poeta ha de alcanzar la cumbre de la palabra mensajera de un mundo nuevo y vaticinadora de la plenitud del ser». En otras palabras, parece que ya está aquí incoado cl oficio de intelectual y de moralista que Aranguren ejercerá con maestría durante décadas: reconocer la realidad de la vida para ir siempre, utópicamente más allá de ella, contra la religión establecida, contra la cultura establecida, y más tarde, señalando también los defectos y carencias de la democracia española establecida.

Ibid., p. 27.

Ibid. p. 67. 


\section{Importancia de la filosofia para la crítica literaria}

En 1952, en un artículo escrito al hilo de la crítica de un libro de José María Valverde, establece Aranguren el cuadro de las posibles relaciones entre poesía y filosofía, con la intención de reivindicar el papel de la filosofía en la crítica literaria. Las dos primeras formas de vinculación tienen sus límites claramente establecidos, mientras que las dos segundas pueden ser muy provechosas para entender la poesía.

Lo que no debe hacerse es reducir la pocsia a mera «ilustración» de la filosofía como aquellos críticos cuyo único propósito es investigar la Weltanschauung del poeta y extraer del poema su sustancia filosófica, pues clementos no conceptuales como el ritmo, la palabra o la musicalidad preceden a la idea y el lenguaje, como diría Bachelard, va siempre por delante de nuestro pensamiento.

La segunda forma de vinculación se produce cuando la crítica poética tiene la pretensión de convertirse en ciencia de la literatura al estilo alemán y reivindica un puesto propio dentro de las ciencias del espíritu, aplicando a las obras literarias los métodos propios de este tipo de ciencias. Aquí Aranguren, con todas las cautelas, aboga por la posibilidad de que el pensamiento de Zubiri pueda proporcionar la base filosófica a los intentos -especialmente a los intentos españoles - de crear una nueva ciencia de la crítica literaria.

En tercer lugar, puede utilizarse la literatura como instrumento básico para una antropología filosófica. En este caso, se trataría de desentrañar - a partir de la obra literaria- el conocimiento del hombre propio de una época determinada, sea ésta el Renacimiento, el Barroco o nuestra contemporaneidad.

Y, por último, se podría dar la vuelta a la relación, viendo ahora la filosofía desde la poesía y usar aquélla como un «método de simbolización» para expresar mediante la filosofía una intuición estrictamente poética. Eliot $\mathrm{y}$, sobre todo en el caso español, Antonio Machado serían ejemplos de este «desquite» que a veces se toman los poetas respecto a los filósofos, mirando la filosofía con una mirada poética.

Pero no se trata de hacer poesía filosófica o filosofía poética, sino de recalcar las aportaciones mutuas. En el caso concreto de la importancia de la filosofía para la crítica literaria, llega Aranguren a la siguiente conclusión:

El prudente uso de la filosofia limpia, por tanto, los ojos y permite ver mejor. Ver mejor y también ver más, porque proporciona ángulos nuevos de visión y posibilita el planteamiento de problemas inéditos ${ }^{10}$.

"J. I. I. Aranguren, «Filosofía y crítica de poesia», en Crítica y meditación, ed. cit., p. 83. En este artículo, Aranguren estudia cómo el conocimiento de tres problemas vivos de la filosofía contemporánea - la temporalidad, el xtalante» y la comunicación-posibilita a José Maria Valverde realizar una crítica literaria de gran calidad en uno de sus primeros libros. 
Estas palabras constituyen un programa de la crítica literaria ejercida durante décadas por Aranguren y en la que su mirada filosófica sobre la literatura nos ha proporcionado nuevos enfoques, nuevas lecturas de las obras literarias, pero también nucvas formas de ver la vida, el mundo y la propia filosofía, como veremos a continuación en los dos últimos apartados de este breve ensayo.

\section{La vida como teatro}

Una de las grandes metáforas que extrae Aranguren de la literatura es la que hace referencia a la vida como teatro. En su breve artículo «El teatro y la vida» comienza hablando del teatro como el género literario más cercano a la vida, ya que la retrata en su fluir temporal, en el acontecer y el actuar de los personajes, para dar en seguida la vuelta a la argumentación y hablar de la vida como teatro, como representación teatral. Este tema de profundas reíces en el estoicismo y en nuestro siglo de oro se actualiza como clave de interpretación sociológica de la vida cotidiana en la obra de Erving Goffman y en su concepción dramatúrgica o teatral de la vida social. No está de más recordar aquí que fue Aranguren uno de los primeros en el panorama sociológico español en hablar de la sociología de la vida cotidiana y en utilizar en este sentido a autores como Simmel y el propio Goffman.

Si «el teatro es la metáfora de la vida de cada día», Aranguren la utiliza de una manera especial para referirse a la política. $Y$ esto a distintos niveles. Por un lado, reconoce en su estudio sobre «Unamuno y nosotros» las raíces históricas del desprecio que la generación del 98 sentía del «teatro político» como una farsa, como una mentira, como la fantasmagoría política de la primera Restauración monárquica. Pero la crítica de Aranguren a Unamuno consiste en la necesidad de retomar el problema intelectual y, sobre todo, moral de la política donde Unamuno lo deja en su drama Soledad: en la necesidad de tomar parte activa en la vida política a pesar de todas sus miserias. Por otro lado, en su arálisis de la democracia establecida plantea Aranguren la necesidad de criticar la conversión de la política contemporánea en espectáculo de meras imágenes de los líderes que generan un culto a la personalidad o, mejor dicho, a la imagen de la personalidad. De esta mancra, la manipulación de las imágenes a través de los medios de comunicación de masas, y especialmente de la telcvisión, sustituye a la libertad y a la elección razonable entre alternativas políticas y pone en peligro a la propia democracia:

Un mecanismo sutil, que opera unidireccionalmente -medios de comunicación de masas y, muy especialmente, la televisión-, cierra el paso a la democracia, que es, por esencia, omnidireccional. De ahí la necesidad, para salvaguardar ésta, de la siempre alerta, vigilante crítica del espectáculo —con frecuencia de la farsa- de 
la política y de las imágenes, en definitiva publicitarias, con las que se enmascara la realidad, poco brillante, de las antidemocráticas «maniobras» políticas ${ }^{1 !}$.

Pero, volviendo de la política a la ética, querría señalar que echo de menos una reflexión de Aranguren acerca del carácter trágico de la ética. Tal vez su talante se distinga radicalmente del sentimiento trágico de la vida unamuniano, pero esto no obsta para que podamos reconocer el carácter de la ética como elección trágica entre cursos de acción alternativos o entre valores últimos en conflicto permanente y de cuya elección depende el tipo de persona que queremos ser, nuestro carácter y también nuestro destino.

Por otro lado, Aranguren lleva hasta el final la metáfora del theatnum mundi aplicada a la vida social y personal, distinguiendo tres niveles: el primero lo forma el calderoniano del Gran Teatro del Mundo, donde cada uno de los personajes realiza, bien o mal, su papel; en segundo lugar, el «Pequeño Teatro» individual, en el que cada cual se cuenta la vida o sueña, imagina, se autoengaña o cjecuta voluntariosamente su proyecto de vida; y entre los dos se situaría el «Teatro de Cámara» de la cotidianidad, en el que la actuación se ha de sujetar a un ritual más o menos rutinario. Y esta metáfora del teatro de la vida nos conduce directamente a la otra gran metáfora literaria -la vida como novela - que cobra una importancia cada vez mayor en la autocomprensión de Aranguren:

Teatro de la vida, teatro del mundo. En este teatro, mientras la representación dura, hay, suele haber toda clase de escenas. Sin embargo, predominantemente, la vida cotidiana cs comedia de cosiumbres, en tanto que la vida existencial y el ahondamiento en la cotidiana es, según predominen la esperanza o la angustia, drama o tragedia. Pero antes, y también simultáneamente, es novela, novela autobiográfica, autonarración $^{12}$.

\section{Novela y narración de la vida: los utextos vivos»}

Con el paso del teatro a la novela entro en mi última consideración on torno a las relaciones entre filosofía y literatura en la obra arangureniana. Y quisiera referirme brevemente primero a su artículo sobre «Don Quijote y Cervantes», artículo en el que Aranguren da un «giro filosófico a la interpretación del libro que más filosofía y sabiduría contiene, entre todos los españoles» ${ }^{13}$. De nuevo nos encontramos con la tesis de la necesidad de buscar la filosofía española en la tradición literaria. Pero no puedo seguir aquí la argumentación

" J. L. L. Aranguren, La democracia establecida. Una crítica intelectual, en el vol. 5 de las Obras Completas, Madrid, Trotta, 1996, p. 558.

12 J. L. L. Aranguren, Moral de la vida cotidiana, personal y religiosa, ed. cit., p. 59.

13 J. L. L. Aranguren, «Don Quijote y Cervantes», en Estudios fiterarios, Madrid, Gredos, 1976, p. 112 . 
de Aranguren en su comparación entre Cervantes y Montaigne, ni su consideración de cómo Cervantes se adelanta a Descartes, ni de cómo puede ser entendido desde nuestro conocimiento de Kant, de Fichte o Schopenhauer; sólo quisiera animar al hipotético y desocupado lector de estas líneas a una nueva lectura de dicho artículo.

En diversas ocasiones -entre otras en la entrevista de Javier Muguerza que aparece en este mismo número de Isegoría - ha utilizado Aranguren la expresión «textos vivos», expresión con la que se llamó en el siglo pasado a los profesores krausistas separados de sus cátedras y que fueron precedente para posteriores expulsiones de profesores. Aranguren amplía el concepto para referirse a todos y cada uno de los mortales, ya que todos nos contamos nuestra vida, nos narramos a nosotros mismos, somos «hombres-relato» en la terminología de Todorov, somos el personaje central de la novela en que consiste nuestra vida:

Pero lo cierto es que todos y cada uno de nosotros somos eso, textos vivos. Textos que nuestro «yo reflexivo» va, por así decirlo, escribiendo, contándose a sí mismo, con más o menos tino, al hilo de la vida protagonizada por nuestro «yo ejecutivo». Contar es como vivir y vivir es como contar o, mejor dicho, contarse, de manera que el mundo vivido y al narrado se solapan inevitablemente. Somos 0 , al menos, nos figuramos ser nuestra propia novela, la «narración narrante» de nuestra vida. Y, como los textos literarios, también los textos que somos requieren de interpretación, razón por la que todos aventuramos, clara o confusamente, nuestra propia hermenéutica ${ }^{14}$.

Todos los individuos elaboramos nuestra propia identidad a través de un proyecto de vida hacia el futuro y de la reflexión sobre nuestro pasado, sobre lo que hemos sido o el camino que hemos hecho hasta el presente. Por ello otorga Aranguren tanto peso en sus análisis literarios a las memorias, autobiografías o confesiones como las de San Agustín. Pero no sólo los escritores consagrados por el canon literario, sino también el común de los mortales nos vamos narrando a nosotros mismos y, mediante estos relatos, construimos nuestra propia identidad: todos consistimos en ese tejer y destejer nuestro propio discurso o texto, dando sentido a la propia experiencia y construyendo la identidad, o una serie de identidades sucesivas. Se trata siempre de «una construción, un constructo nuestro, urdido por nosotros como una trama, tejido o texto que, otras veces, llamamos también dis-curso» ${ }^{15}$.

Pero, además, Aranguren insiste en el carácter autobiográfico de toda obra escrita. Y tal vez de una manera especial se esté refiriendo a sí mismo, pues

${ }^{14}$ Palabras de Aranguren en la entrevista de Javier Muguerza «Del aprendizaje al magisterio de la insumisión", en E. López-Aranguren, J. Muguerza y $I$. M. Valverde, Retrato de Jasé Luis L. Aranguren (Madrid, Galaxia Gutenberg-Círculo de Lectores, 1993, p. 88), y reproducida en el presente número de Isegorfa. Formulaciones análogas de Aranguren pueden encontrarse en su libro Moral de la vida cotidiana, personal y religiosa, Madrid, Tecnos, 1987, especialmente las pp. 55-71.

is J. L. L. Aranguren, Moral de la vida cotidiana, personal y religiosa, ed. cit., p. 64. 
él fue construyendo de manera consciente el entramado de su vida con el de su obra, uniendo de manera paradigmática el texto vital con el texto escrito y sicndo para varias generaciones de españoles un ejemplo de texto vivo durante décadas. Al cumplirse el primer aniversario de su muerte quisiera recordar que, como bien decían los antiguos, kal hablar de experiencia humana, nada es más perdurable e inmortal que los libros». La inmortalidad de la sabiduría es un viejo tópico barroco que nos encontramos, por ejemplo, en el emblema de Florentius Schoonvius, publicado a comienzos del siglo xvil y al que se refiere Walter Benjamin en algún pasaje. Aquí voy a transcribir simplemente la descripción del emblema que hace el estudioso del barroco Gottfried Kirchner:

El lemma (título) del emblema - «ivitur ingenio» - subraya la continua vida del espíritu. La pictura (imagen) muestra el esqueleto de la muerte frente a un paisaje en ruinas que representa el destino y la vanidad del mundo; la muerte tiene en sus manos o toca con sus pies la corona y el cetro, atributos transitorios del poder terrenal. Cerca se ve una roca con un libro sobre el que crece la hiedra y sobre el que se ve una serpiente enrollada, ambos signos emblemáticos de la duración eterna. La subscriptio (subtítulo) muestra la conexión entre los diversos niveles de la composición gráfica... ${ }^{16}$

La traducción de este subtítulo a román paladino reza como sigue:

Los gobemantes caen, las ciudades perecen, nada

de lo que un día fue Roma permanece.

El pasado es vacío, nada.

Sólo esos asuntos de la sabiduría y

los libros que dan fama y respeto

escapan a la pira funeraria

creada por el tiempo y la muerte.

La muerte no tiene, por consiguiente, la última palabra. En el caso de Aranguren nos quedan los bellos recuerdos de su amistad, de tantos momentos y esfuerzos vividos juntos y, de manera especial, nos quedan los libros «que le han dado fama y respeto» $y$ en los que ha expresado lo mejor de su trama vital.

${ }^{16}$ G. Kirchner, Fortuna in Dichtung und Emblematik des Barock. Tradition und Bedeutungwwandeln eines Motivs, Stuttgart, Metzler, 1970, p. 78. Citado por S. Buck-Morss, Dialéctica de la mirada. Walter Benjamin y el proyecto de los pasajes, Madrid, Visor, 1995, pp. 185-186. 